Est Ag 46 (2011) 275-290

\title{
La gracia de Dios en Cervantes
}

\author{
JosÉ VEGA BLANCO*
}

RESUMEN: El tema de la gracia divina en Cervantes es rico y abundante. Esta gracia nos hace más de Dios, nos introduce en el evangelio. Su unción nos lleva a Cristo, nuestro maestro que es suave. Esto predica don Quijote a los que no saben perdonar a sus enemigos y quieren vengarse de ellos. Libros, acontecimientos, encuentros, diálogos, obras buenas van dejando sus semillas. La gracia es luz del hombre e infinita misericordia de Dios. Quizás hoy estemos en mejores condiciones que nunca para valorar este cristianismo. Dios no es algo lejano, sino presente y misericordioso, Providencia amorosa pero cada uno con su responsabilidad. El hombre no solo cuenta con su razón para orientarse. Estas son las creencias religiosas fundamentales.

PALABRAS CLAVE: misericordia, pecado, amor de Dios, esperanza.

ABSTRACT: The topic of divine grace is amply discussed by Cervantes. It makes us more than God, introduces us into the gospels. As graced persons, we are led to Christ, our master, who is meek. Don Quijote preaches this to all who know not to forgive their enemies and want to avenge them. Books, events, encounters, dialogues, good works, all do sow their seeds. Grace is the light of mankind and God's infinite mercy for it. Perhaps we are today in a better condition than ever to value this Christianity. God is not distant, but present and merciful; is loving Providence, letting each one with one's own responsibility. In order to orient oneself in life, one does not rely on reason alone. There are also the basic religious beliefs.

KEY WORDS: Mercy, sin, love of God, hope.

\footnotetext{
${ }^{*}$ Estudio Teológico Agustiniano,Valladolid.
} 


\section{Significados no religiosos}

La gracia es don innato y es habilidad adquirida que hacen agradable a una persona ${ }^{1}$. "Todas estas gracias, adquiridas y puestas sobre la natural suya, poco a poco fueron encendiendo el pecho de Ricaredo". . Gracia significa benevolencia y amistad, favor que a alguien da otro. "Buen suceso / y agüero espero y te doy, / porque irás en gracia mía"s. Don Fernando intercede por Sancho. "Debe vuestra merced, señor don Quijote, perdonarle $\mathrm{y}$ reducirle al gremio de su gracia, sicut erat in principio, antes que las tales visiones le sacasen de juicio"4. "Como es la misma comedia, con la cual quiero, Sancho, teniéndola en tu gracia, y por el mismo consiguiente a los que la representan y a los que las componen"s. Gracia es el favor y acogida que se implora. Es lenguaje usual de enamorados. "Si ha hallado esta cautiva / alguna gracia ante ti". "Salgo de la pertinacia / do me tuvo mi malicia / y el estar en tu desgracia, / y apelo de tu justicia / ante el rostro de tu gracia; / que, si a mi poco valor / no le quilata el favor / de tu gracia conocida, / presto dejaré la vida / en las manos del dolor"7. Don Quijote quiere merecer la gracia de Dulcinea y se entrega a duras penitencias en Sierra Morena, "estaba determinado de no parecer ante su hermosura fasta que hobiese fecho fazañas que ficiesen digno de su gracia" ${ }^{8}$. Usando el lenguaje arcaizante de sus admirados modelos. Sancho, hincado de rodillas ante una de las tres labradoras, implora: "reina y princesa y duquesa de la hermosura, vuestra altivez

${ }^{1}$ Abreviaturas de las obras de Miguel de Cervantes citadas en este artículo. CP- "Coloquio de los Perros", en Novelas ejemplares, edición de Jorge García López, estudio preliminar de Javier Blasco, presentación de Francisco Rico, Galaxia Gutenberg / Círculo de lectores, Barcelona 2005; EI- "La Española Inglesa", Novelas ejemplares, edic. cit.: GI- "La Gitanilla", Novelas ejemplares, edic. cit.;AL-"El Amante liberal", Novelas ejemplares, edic. cit.; LV- "El Licenciado Vidriera, Novelas ejemplares, edic. cit. ; GE-"El Gallardo español", en Obras completas, edición de Ángel Valbuena Prat, Aguilar, Madrid 1960; BA-"Los Baños de Argel", edic. cit.;TA- "El Trato de Argel", edic cit. GS-"La Gran Sultana", edic. cit. ; RD-"El Rufián Dichoso", edic. cit. LG-"La Galatea", edición de Francisco López y María Teresa López García- Berdoy. Cátedra, Madrid 1999; PS- "Los trabajos de Persiles y Sigismunda", edición de Carlos Romero Muñoz, Cátedra, Madrid 2003; QM-"Don Quijote de la Mancha", edición dirigida por Francisco Rico, Galaxia Gutenberg / Círculo de Lectores, Barcelona 2004, cito la parte, el capítulo y la página; VP-PV, Viaje del Parnaso-Poesías varias, edición de Elías L. Rivers, Espasa-Calpe, Madrid 1991.

${ }^{2} \mathrm{EI}, 219$.

${ }^{3} \mathrm{GE}, \mathrm{II}, 200$.

${ }^{4} \mathrm{QM}, \mathrm{I}, 46,585-586$.

${ }^{5} \mathrm{QM}, \mathrm{II}, 12,784$.

${ }^{6} \mathrm{GS}, \mathrm{I}, 375$.

${ }^{7} \mathrm{LG}, \mathrm{V}, 536$.

${ }^{8}$ QM, I, XXIX, 366. 
y grandeza sea servida de recibir en su gracia y buen adelante al cautivo caballero vuestro" . A don Quijote "la Duquesa le preguntó si quedaba en su gracia Altisidora"10.

El primer texto del último grupo nos habla del cautivo que se acoge a la gracia de su señor. De la misma manera el vasallo sirve a su señor y éste le otorga su gracia. La vida es servicio del inferior al superior, y, al hacerlo, aquel recibe la merced, la gracia de participar de una dignidad más elevada, que de otra manera no podría alcanzar, adquiere una nueva naturaleza, se naturaliza y, al revés, el vasallo que se desarraiga de su señor, se desnaturaliza y pierde su gracia. Naturarse y desnaturarse eran términos usuales en el lenguaje de La Edad Media. La gracia es participación de la naturaleza divina. El hombre deja su villanía fuera de palacio y, al servir al Rey, participa de las cualidades reales, se transforma en un nuevo ser. Queda elevado a una nueva naturaleza. La gloria es la naturalización definitiva, sin posibilidad de desnaturalizarse. Si la gracia es una nueva naturaleza, una sobrenaturaleza, nada más lógico que, al conceptualizarla teológicamente, se acudiese al lenguaje filosófico con que se explicaba la naturaleza.

\section{Providencia}

Teóricamente, como ya vimos, los autores distinguían orden natural y orden sobrenatural. Aquel estaba organizado por la Providencia. En este entraban la gracia y la Predestinación. Pero en la práctica no siempre era fácil decidir si un don se refería a un orden o a otro. Cervantes usa alguna vez la palabra gracia referida al orden natural. Aunque por el vocabulario demos aquí los textos, por su concepto tendrían que ir al capítulo de la Providencia. Por la gracia espera Sancho conseguir el encuentro con los suyos. El encuentro con las personas queridas era uno de los bienes que se agradecían a la Providencia. "Si Dios me diere tanta gracia, que algún día me vea con mi mujer y mis hijos"11. Auristela, a punto de morir, comienza a recobrar la salud, "la cual, dando gracias al cielo por la merced y regalos que le iban haciendo, así en la enfermedad como en la salud"12.

\footnotetext{
${ }^{9} \mathrm{QM}, \mathrm{II}, \mathrm{X}, 770$.

${ }^{10}$ QM, II, LXX, 1308.

11 QM, I, XXV, 303.

${ }_{12}$ PS, IV, X, 690.
} 


\section{Elipsis}

Entre los muchos casos de elipsis registrados en Cervantes hay uno especial por medio de un pronombre se alude a un nombre contenido en un verbo o en otro nombre. "Por vida del gobernador, y así Dios me le dejé gozar"13. "Yo adoro a esa gitana: moriré contento si muero en su gracia, y sé que no nos ha de faltar la de Dios, pues entrambos habremos guardado honestamente y con puntualidad lo que nos prometiste"14. "El cuento es muy bueno, y vos, buen Pedro, le contáis con muy buena gracia, la del señor no me falta, que es la que hace al caso" 15 . "Os doy infinitas gracias, y ahora espero en la del cielo, que, pues, nos sacó de tanta miseria a todos, nos ha de dar en este, que pretendemos, felicísimo viaje"16.

\section{El pecado}

La Cañizares vive gustosa con las cadenas de su pecado, aunque sabe que Dios está pronto a perdonarla. La costumbre se hace naturaleza y el alma se deja estar, indolente, en el lecho que ella misma se ha labrado. Sobre sus palabras ya hemos escrito. Recordemos solo algunas. “¿Por qué no deja de ser bruja pues sabe tanto, y se vuelve a Dios, pues sabe que está más pronto a perdonar pecados que a permitirlos? Que la costumbre del vicio se vuelve en naturaleza. Entorpece aun en la fe, de donde nace un olvido de sí misma, y ni se acuerda de los temores con que Dios la amenaza, ni de la gloria con que la convida; y en efecto, como es pecado de carne y de deleites, es fuerza que amortigüe todos los sentidos, y los embelese y absorte, sin dejarlos usar sus oficios como deben; $y$, así, quedando el alma inútil, floja y desmalazada, no puede levantar la consideración siquiera a tener algún buen pensamiento; y así, dejándose estar sumida en la profunda alma de su miseria, no quiere alzar a la de Dios, que se la está dando, por sola su misericordia para que se levante. Yo tengo una destas almas que te he pintado. Todo lo veo y todo lo entiendo; y como el deleite me tiene echados grillos a la voluntad, siempre he sido y seré mala"17. "Si lo decís por la Camacha, ya ella pagó su pecado, y está donde Dios se sabe"18.

\footnotetext{
${ }^{13}$ QM, II, XLVII, 1098.

${ }^{14} \mathrm{GI}, 104$.

${ }^{15} \mathrm{QM}, \mathrm{I}, \mathrm{XII}, 144$.

${ }^{16} \mathrm{PS}, \mathrm{I}, \mathrm{IX}, 194$.

${ }^{17} \mathrm{CP}, 599$.

${ }^{18} \mathrm{CP}, 589$.
} 
Roque Guinart "a mí me han puesto en él no sé qué deseos de venganza, que tienen fuerza de turbar los más sosegados corazones. Yo de mi natural soy compasivo y bienintencionado, pero, como tengo dicho, el querer vengarme de un agravio que se me hizo, así da con todas mis buenas inclinaciones en tierra, que persevero en este estado, a despecho y pesar de lo que entiendo; y como un abismo llama a otro y un pecado a otro pecado, hanse eslabonado las venganzas de manera que no solo las mías, pero las ajenas tomo a mi cargo. Pero Dios es servido de que, aunque me veo en la mitad de mi laberinto de mis confusiones, no pierdo la esperanza de salir dél a puerto seguro. (Don Quijote) Señor Roque, el principio de la salud está en conocer la enfermedad y en querer tomar el enfermo las medicinas que el médico le ordena. Vuestra merced está enfermo, conoce su dolencia, y el cielo, o Dios, por mejor decir, que es nuestro médico, le aplicará medicinas que le sanen, las cuales suelen sanar poco a poco, y no de repente y por milagro; y más, que los pecadores discretos están cerca de enmendarse que los simples; y pues vuestra merced ha mostrado en sus razones su prudencia, no hay sino tener buen ánimo y esperar mejoría de la enfermedad"19.

Cervantes habla de obras hechas en pecado. Tales obras no valen nada, era la expresión común. Dios no oye a los pecadores. "Tenía unas sombras y lejos de cristiana" ${ }^{20}$. La misericordia de Dios no excluye a nadie y los caminos de la gracia son inescrutables. Dios es médico universal y a quien se reconoce enfermo le aplicará la medicina. También Maritornes reza por el éxito del cura y el barbero, que pretenden sacar a don Quijote de Sierra Morena. "Despidiéronse de todos, y de la buena de Maritornes, que prometió de rezar un rosario, aunque pecadora, porque Dios les diese buen suceso en tan arduo y tan cristiano negocio como era el que habían emprendido" 21 . Doña Lorenza censura la condición desabrida de su marido. "Todas vuestras buenas obras las hacéis en pecado mortal; dístelas dos docenas de reales, acompañados con otras dos docenas de injurias, boca de lobo lengua de escorpión y silo de malicia"22.

\section{La gracia de Dios}

"Pues esta fama, estas gracias, estas prerrogativas, como llaman a esto -respondió Sancho- tiene los cuerpos y las reliquias de los santos, que con

\footnotetext{
${ }^{19}$ QM, II, LX, 1229-1230.

${ }^{20} \mathrm{QM}, \mathrm{I}, \mathrm{XVII}, 202$.

${ }^{21}$ QM, I, XXVII, 328.

${ }^{22}$ VC, VIII, 236.
} 
aprobación y licencia de nuestra santa madre Iglesia tienen lámparas, velas, mortajas, muletas, pinturas, cabelleras, ojos, piernas, con que aumentan la devoción y engrandecen su cristiana fama. Los cuerpos de los santos, o sus reliquias, llevan los reyes sobre sus hombros, besan los pedazos de sus huesos, adornan y enriquecen con ellos sus oraciones y sus más preciados altares"23.

Un paso más y nos encontramos con don Quijote. La gracia ha hecho su obra. - “¡Bendito sea el poderoso Dios, que tanto bien me ha hecho! En fin, sus misericordias no tienen límite, ni las abrevian ni impiden los pecados de los hombres.

Estuvo atenta la sobrina a las razones del tío y pareciéronle más concertadas que él solía decirlas, a lo menos en aquella enfermedad, y preguntole.

-¿Qué es lo que vuestra merced dice, señor? ¿Tenemos algo de nuevo?¿Qué misericordias son éstas, o qué pecados de los hombres?

Las misericordias -respondió don Quijote-, sobrina, son las que en este instante ha usado Dios conmigo, a quien, como dije, no las impiden mis pecados. Yo tengo juicio ya libre y claro sin las sombras caliginosas de la ignorancia que sobre él me pusieron mi amarga y continua leyenda de los detestables libros de las caballerías. Ya conozco sus disparates

y sus embelecos, y no me pesa sino que este desengaño ha llegado tan tarde, que no me deja tiempo para hacer alguna recompensa, leyendo otros que sean luz del alma"24.

Hay en las palabras de don Quijote un tono de alegría rebosante, un aire incontaminado de alborada, de nacimiento a una vida nueva, el canto de júbilo del que se ve arrebatado, sin peso, por las riberas de un mundo nuevo, porque un chorro de luz esplendorosa le ilumina los más secretos entresijos. Don Quijote, al despertar del sueño, "dando una gran voz", celebra las misericordias de Dios desde el abismo de sus pecados. No hace alarde de las obras, no hace mandas religiosas, ni se dedica a encargar sufragios y obras pías que aseguran su salvación. Confía en las misericordias de Dios, que no tienen límite.

"Ya me son odiosas todas las historias de la andante caballería; ya conozco mi necedad y el peligro en que me pusieron haberlas leído; ya, por misericordia de Dios escarmentado en cabeza propia, las abomino" 25 . De sus

\footnotetext{
${ }^{23}$ QM, II, VIII, 756.

${ }^{24}$ QM, II, LXXIIII, 1330.

${ }^{25}$ QM, II, LXXIIII, 1330-1331.
} 
errores se arrepiente. "Perdóname, amigo, de la ocasión que te he dado de parecer loco como yo, haciéndote caer en el error en que yo he caído de que hubo y hay caballeros andantes en el mundo"26. Quiere nuevos libros, pero ahora libros que sean luz del alma, que alumbren sobre lo que es y no es, que ayuden a formar el propio juicio, "libre y claro", y despierten la discreción. Por consiguiente, es la Providencia la que ha guiado a don Quijote, la que le ha traído a la situación actual, la que ha revoloteado en torno a él a través de encuentros, humillaciones y fracasos. Al final de la novela, como siempre, el azar se revela como Providencia. No hay fortuna, sino Providencia. Las palabras de don Quijote no permiten la duda. Todos son signos, señales que la Providencia va dejando en el laberinto de confusiones en que don Quijote vive enajenado, extraviado, y que la van llevando hacia la salida de sus errores.

\section{La gracia y las obras}

"Cuanto más que el tomar venganza injusta, que justa no puede haber alguna que lo sea, va derechamente contra la santa ley que profesamos, en la cual se nos manda que hagamos bien a nuestros enemigos y que amemos a los que nos aborrecen, mandamiento que aunque parece algo dificultoso de cumplir, no lo es para aquellos que tienen menos de Dios que del mundo y más de carne que espíritu; porque Jesucristo, Dios y hombre verdadero, que nunca mintió, ni pudo ni puede mentir, siendo legislador nuestro dijo que su yugo era suave y su carga liviana, y así, no nos había de mandar que fuese imposible al cumplirla. Así que, mis señores, vuesas mercedes están obligadas por leyes divinas y humanas a sosegarse"27. Todos están obligados a cumplir los mandamientos de Cristo por muy difíciles que resulten. Don Quijote señala uno: amar a los enemigos, no tomar venganza. En realidad no es difícil, sino para aquellos "que tienen menos de Dios que del mundo, y más de carne que del espíritu". El yugo de Cristo es "suave y liviano".

"Con todo confío en Dios, / que su poderosa mano / ha de librar a los dos / de este temor, que no es vano; / y si estuvieran cerrados / los cielos por mis pecados, / por no oír mi petición, / dispondré mi corazón / a casos más desastrados. / No triunfará el inhumano / del alma; del cuerpo, sí, / caduco, frágil y vano" ${ }^{28}$. Martirio "es merced particular / que Dios a quien él quiere.

\footnotetext{
${ }^{26}$ QM, II, LXXIIII, 1332-1333.

${ }^{27} \mathrm{QM}, \mathrm{II}, \mathrm{XXVII}, 937-938$.

${ }^{28} \mathrm{GS}, \mathrm{I}, 369$.
} 
/ Al cielo le pediré, / ya que no merezco tanto, / que a mi propósito santo / de su firmeza le dé; / haré lo que fuere en mí, / y en silencio, en mis recelos, / daré voces a los cielos" ${ }^{29}$. Un turco contesta a doña Catalina, que le declara de "ser cristiana. / $¿$ Tengo yo a cargo tu alma, / o soy Dios para inclinarla / o ya de hecho llevarla / donde alcance eterna palma?"30. El mundo ofrecerá sus tesoros, el demonio hará guerra, "pero no podrán, Dios mío, / como yo de vos confío, / mudar mi buena intención"31. Es doña Catalina de Oviedo quien dice las últimas palabras, la misma que se dirige a Cristo, que nos cobró en el árbol de la cruz. "A ti me vuelvo en mi afición amarga, / y a ti toca, Señor, el darme ayuda: / que soy cordera de tu aprisco ausente / y temo que, a carrera corta o larga, / cuando a mí daño tu favor me acuda, / me ha de alcanzar esta infernal serpiente" 32 "Reza, reza, Catalina, / que sin la ayuda divina / duran poco humanos bienes"33. "Mártir soy en mi deseo, / y, aunque por ahora duerma / la carne frágil y enferma / en este maldito empleo, / espero en la luz que guía / al cielo al más pecador, / que ha de dar su resplandor / en mi tiniebla algún día, / y de esta cautividad, / adonde reine ofendida, / me llevará arrepentida / a la eterna libertad"34.

Un pasaje de Los Baños de Argel recuerda el triple estado de la naturaleza, de ley y de gracia. "Dejo aparte que no tengas / ley con quien tú alma avengas, / ni la de gracia ni escrita, / ni en la iglesia ni en mezquita / a encomendarte a Dios vengas. / Con todo de tu fiereza, / no pudiera imaginar / cosa de tanta extrañeza / como es venirte a faltar / la ley de naturaleza" 35 . El niño Francisco "pues sepa que he de burlarle / aunque me dé montes de oro. / De estas gracias ¿que decís? / que son sobrenaturales"36. "Quien con amor amargo se entretiene, / y al duro yugo de su servidumbre / el flaco cuello ya inclinado tiene, / si del cielo no viene nunca lumbre / que aquella ceguedad de los sentidos / con claros rayos de razón alumbre, / todos estos remedios son perdidos; / que al fin irán por tierra derivados / los amigos consejos más sabidos"37 “ ¿Cómo he tenido y tengo la esperanza / puesta en el Hacedor de tierra y cielo / por cristiana y segura confianza, / por su bondad, aun tengo el casto velo / guardado, y con su ayuda santa espero /

\footnotetext{
${ }^{29} \mathrm{GS}, \mathrm{II}, 381$.

${ }^{30} \mathrm{GS}, \mathrm{II}, 382$.

${ }^{31} \mathrm{GS}, \mathrm{I}, 370$.

${ }^{32} \mathrm{GS}, \mathrm{I}, 377$.

${ }^{33} \mathrm{GS}$, II, 388.

${ }^{34}$ GS, III, 392.

${ }^{35} \mathrm{BA}, \mathrm{I}, 286$.

${ }^{36}$ BA, II, 297.

${ }^{37}$ TA, II, 129.
} 
no tener de mancharle algún recelo"38 "¿Qué no ha de ser posible, pobre Aurelio, / es defenderte de esta mora infame, / que por tantos caminos te persigue? / Si será, sí, si no me niegue el cielo / el favor que hasta aquí no me ha negado"39. En un texto, ya citado, se dice que el diablo no podrá vencernos. "Y para que no rehuyas / de verte con él abrazos. / Dios rompe y quiebra los lazos / que pasan las fuerzas tuyas"40. "La que es más humilde planta, / si la subida endereza, / por gracia o naturaleza / a los cielos se levanta. / Haga yo lo que en mí es, / que a ser buena me encamine, / y haga el cielo y determine / lo que quisiere después" ${ }^{41}$. Berganza hace propósitos de no murmurar. "A lo menos, yo haré de mi parte mis diligencias, y supla las faltas el cielo" $"$.

Dijo a esta sazón el jadraque,"pero no por esto dejo de ser cristiano, que las divinas gracias la da Dios a quien él es servido"43 "¡Cristiana, cristiana y libre, y libre por la gracia y misericordia de Dios!", dice Rafala ${ }^{44}$. "Por muy muchos y varios casos he venido a este miserable estado en que me veo; y aunque es tan peligroso, siempre por favor del cielo he conservado en él la entereza de mi honor, con la cual vivo contenta en mi miseria, por lo cual os ruego, señor, siquiera por la sangre que de cristiano tenéis, me aconsejéis en mis trabajos".

Y por ella, por Dulcinea, se mantiene firme en sus aventuras y hazañas. $\mathrm{El}$ amor le exige acometer empresas de las que Dulcinea es el alma. Al final, "ella pelea y vence en mí, y yo vivo y espero en ella, y tengo vida y ser" ${ }^{46}$. "Con esa manera de amor -dijo Sancho- he oído yo predicar que se ha de amar a Nuestro Señor, por sí solo, sin que nos mueva esperanza de gloria temor de pena, aunque yo le querría amar y servir por lo que pudiese" 47 .

Costancica "ella, lo primero y principal, es devotísima de Nuestra Señora; confiesa y comulga cada mes" ${ }^{\text {" }}$. La madre siendo viuda de un gran caballero "se retiró a vivir a una aldea suya, y allí, con recato y con honestidad grandísima, pasaba con sus criados una vida sosegada y quieta" ${ }^{29}$.

\footnotetext{
${ }^{38} \mathrm{TA}, \mathrm{III}, 132$.

${ }^{39} \mathrm{TA}, \mathrm{III}, 133$.

${ }^{40} \mathrm{TA}, \mathrm{III}, 134$.

${ }^{41} \mathrm{GI}, 93$.

${ }^{42} \mathrm{CP}, 563$.

${ }^{43} \mathrm{PS}$, III, XI, 548.

${ }^{44} \mathrm{PS}, \mathrm{III}, \mathrm{XI}, 552$.

${ }^{46} \mathrm{QM}, \mathrm{I}, \mathrm{XXX}, 386$.

${ }^{47}$ QM, I, XXXI, 398.

${ }^{48} \mathrm{IF}, 430$.

${ }^{49} \mathrm{IF}, 434$.
} 


\section{EI Caballero del Verde Gabán}

El Caballero del Verde Gabán nos da cuenta de su vida apacible y sosegada de hidalgo de aldea, con su mujer, sus hijos y sus amigos. Limitémonos al aspecto religioso.

Don Diego de Miranda "hojeo más los que son profanos que los devotos, como sean de honesto entretenimiento, que deleiten con el lenguaje y suspendan con la invención. Son mis convites limpios y aseados y nonada escasos; ni gusto de murmurar ni consiento que delante de mí se murmure; no escudriño las vidas ajenas; oigo misa cada día, reparto de mis bienes con los pobres, sin hacer alarde de las buenas obras, por no dar entrada en mi corazón a la hipocresía y vanagloria, enemigos que blandamente se apoderan del corazón más recatado; procuro poner en paz los que sé que están desavenidos; soy devoto de Nuestra Señora y confío siempre en la misericordia de Dios Nuestro Señor" 50 .

A Sancho le parece una vida "buena y santa. Me parece vuesa merced el primer santo a la jineta que he visto en todos los días de mi vida.

No soy santo -respondió el hidalgo-, sino gran pecador; vos sí, que debéis de ser bueno, como vuestra simplicidad lo muestra"51.

Un caballero, casado, que se presenta como "más que medianamente rico", que gusta de "poner en paz a los desavenidos", que convida a sus amigos y sus convites son "limpios y aseados y no nada escasos". El caballero ni murmura ni escudriña las vidas ajenas, ama el sosiego y la quietud, la dorada moderación. Es prudente y discreto, repartidor de sus bienes con los pobres. Don Diego no alardea de sus obras, no es fariseo, confía en la misericordia infinita de Dios y se siente gran pecador. En su lugar nos dejó un retrato contenido y simpático. "Sencillo, equilibrado y libre de ambición, limitando aspiraciones y contentándose con el sosiego de la paz hogareña, don Diego encarna la dorada moderación de los antiguos. No es dado a la poesía y lamenta que su hijo lo sea. Lo que le realza y avalora es la práctica de las virtudes cristianas. No hace milagros, como cree ingenuamente Sancho al oírle contar su vida; pero sin exceder del nivel medio, da un ejemplo de noble posibilidad moral humildemente realizada. Es lo que Alonso Quijano el Bueno, cuando recobró el juicio en su lecho de muerte, hubiera querido ser. Góngora salva la idea de aldea mediante la captación de la belleza

${ }^{50} \mathrm{QM}, \mathrm{II}, \mathrm{XVI}, 823$.

${ }^{51}$ QM, II, XVI, 823-824. 
natural; Cervantes, haciendo que el hidalgo lugareño cumpla un ideal de humanidad que tiene entre sus virtudes la de no ostentarlas" 52 .

\section{Un religioso de la Orden de Predicador}

El rufián Lugo, futuro P. Cruz, entra en religión, desafiando a todos los demonios. "Y en mi Dios bueno confío / que os he de vencer a todos"53. Cuando el P. Cruz se dirige a confesar a doña Ana, reza: “FFavorezca mis intentos / Dios de quien siempre confío!"54. Doña Ana desconfía de la misericordia de Dios, que no puede "sin más ni más, perdonar / a tan grande pecadora. / De su parte has de esperar / que de la tuya no esperes. / La mayor ofensa haces / a Dios que puedes hacer: / que en no esperar y temer / parece que le deshaces, / pues vas contra el atributo / que él tiene de omnipotente, / pecado el más insolente, / más sin razón y más bruto"55. Doña Ana resiste a la gracia.Termina por decir que para ella no existe Dios, "que esconda misericordia / el rostro, y no la justicia. / Sea servida de encomendarme / a Dios, que quiero mostrarme sucesor en su pelea. / Mirad donde queréis vuestra alma vaya: / escogedle la patria a vuestro gusto. / La justicia de Dios me tiene a raya: / no me ha de perdonar, por ser tan justo"56. El P. Cruz aprieta el alma, próxima a la muerte, debe dejar el temor y asirse a la esperanza. Pero el alma no está sola. Cuenta, si quiere, con la presencia enardecedora de la Virgen, del Ángel de la Guarda, con el auxilio de la gracia. Es un error entrar en el palenque sin ánimo de victoria. "En el campo estáis, Señora, / la guerra será esta tarde: / mirad que no os acobarde / el enemigo en tal hora. / Confiad en el padrino / y en el juez, que es mi Dios. / Dejadme, que, en conclusión, / tengo el alma de madera / que no quiero, aunque Dios quiera / gozar de indulto y perdón"57. Lucifer se lamenta de que se acierte "a salvar en un corto y breve instante / un ladrón que no tuvo semejante; / la pecadora pública arrebata / de sus pies el perdón de sus pecados" "58. "Apenas a la vista se le ofrece / doña Ana al Padre Cruz, sin la fe pura / que a nuestras esperanzas fortalece, / cuando con caridad firme y segura, / hizo con ella un cambio de tal suerte, / que cambió su desgracia en

\footnotetext{
${ }^{52}$ LAPESA, RAFAEL, De la Edad Media a nuestros días, Editơrial Gredos, Madrid 1967, 230-231.

${ }^{53} \mathrm{RD}, \mathrm{I}, 342$.

${ }^{54} \mathrm{RD}, \mathrm{II}, 351$.

${ }^{55} \mathrm{RD}, \mathrm{II}, 351-352$.

${ }^{56} \mathrm{RD}, \mathrm{II}, 352$.

${ }^{57} \mathrm{RD}, \mathrm{II}, 353$.

${ }^{58} \mathrm{RD}, \mathrm{III}, 361$.
} 
gran ventura. / Su alma de las garras de la muerte / eterna arrebató, y volvió a la vida, / y de su pertinacia la divierte, / la cual como se viese enriquecida / con la dádiva santa que el bendito / Padre le dio sin tasa y sin medida" $" 59$.

El P. Cruz se ve llagado de lepra. Se ha cumplido el cambio y tiene que pagar las deudas de la pecadora, ahora enriquecida "con la dádiva santa que el bendito / padre le dió sin tasa y sin medida"60. El P. Cruz "cubierto el rostro de lepra / que lo es en santidad y en la fiereza / cuya fealdad a nadie le da en rostro. / Acompaña a la lepra la flaqueza; / No me puedo tener. ¡Dios sea bendito, / que así a pagar mi buen deseo empieza"61. "¡Y que tuviese Dios por bueno y justo / tal cambalache! Estúvose la dama / al pie de cuarenta años en sus vicios / desesperada de remedio alguno; / llega este otro buen alma, y dale luego / los tesoros de gracia que tenía / adquiridos por Cristo y por sus obras. / ¡Gentil razón, gentil guardar justicia / y gentil igualar de desiguales / y contrapuestas prendas; gracia y culpa / bienes de gloria y del infierno males"62. Los demonios se preparan lamentándose de que Dios les arrebate el alma "en un instante / nos quita de las manos de Dios al alma / que se arrepiente y sus pecados llora; / cuanto más que ésta estaba enriquecida / con las gracias del fraile hi de bellaco"63.

Se confía en Dios, la gracia está siempre presente, se siente la nada del hombre, se repite una y otra vez la vida del penitente del P. Cruz y se enumeran sus obras para que nadie se llame a engaño. Los méritos son de Cristo y de sus obras. No confía en sus obras, pero las hace. Confía en Dios, pero no se olvida de las penitencias. Dios y las obras devotas le salvan. Y no solo sus obras son meritorias para él mismo, sino que las traspasa a una pecadora, comprometiéndose a expiar por los pecados del prójimo, a imitación de Cristo. Es un ejemplo de caridad llevada al límite y una ejemplificación escénica de la Comunión de los Santos.

\section{Las obras tibias}

"Y advierte Sancho que las obras de caridad que se hacen tibia y flojamente no tienen mérito ni valen nada" ${ }^{64}$.

\footnotetext{
${ }^{59} \mathrm{RD}, \mathrm{III}, 355$.

${ }^{60} \mathrm{RD}, \mathrm{III}, 355$.

${ }^{61} \mathrm{RD}, \mathrm{III}, 355$

${ }^{62} \mathrm{RD}, \mathrm{III}, 356$.

${ }^{63} \mathrm{RD}, \mathrm{III}, 356$

${ }^{64}$ QM, II, XXXVI, 1016.
} 
Rodríguez Marín en la edición de 1916-1917: "Y estuvo bien borrado, porque, desde el punto teológico y de todas maneras, algo valen esas obras así hechas, aunque valgan poco" 65 . Tras aducir testimonios de Gómez García, Francisco de Osuna, Bernardino de Laredo, Juan de Medina, Alonso de Orozco y Jerónimo Gracián, concluye: "Por todo lo antedicho, no acierto a explicarme en qué Cervantes para que mandaran borrar en su libro un concepto que de san Pablo acá viene corriendo como verdad palmaria"

Marcel Bataillon: "Pero él sabe que lo esencial del cristianismo no consiste en el ascetismo del religioso. La fe de Cervantes, lejos de ser la fe del carbonero, es una fe que se remite al evangelio y que está iluminada por el sentimiento de la gracia, No es fe muerta, cortada de la acción, sino fe viva, engendradora de obras" timo y nada vulgar del cristianismo de Cervantes, con el hecho de su predilección por el apóstol san Pablo y con el abolengo de su religiosidad"68.

Como estas palabras cayeron en el Índice inquisitorial, han atraído la atención de los comentaristas. El Índice expurgatorio del Cardenal Zapata (Sevilla 1632), el primero que se publicó después de la impresión ${ }^{69}$.

Realizar "las obras de caridad que se hacen tibia y flojamente no tienen mérito ni valen nada". Los inquisidores tenían que reaccionar ante la mera mención del tema del mérito, la cuestión sobre el mérito, la gracia y la predestinación. San Pablo: "Si no tengo amor, no pasa de ser una campana ruidosa o unos platillos estridentes... Que si no tengo amor, no soy nada... Si no tengo amor de nada, me sirve" "70. Se habla de "las obras de caridad que se hacen tibia y flojamente". San Pablo se habla de las obras del mérito, esencialmente buena. El inquisidor Zapata "mandó borrarla, porque en realidad no es correcta en sentido teológico. Toda obra que sea verdaderamente de caridad se tiene que hacer en gracia, y toda obra hecha en gracia tiene mérito para la propia salvación" "11. Cervantes habla de la naturaleza y sigue siendo criatura, esencialmente buena ${ }^{72}$.

\footnotetext{
${ }^{65}$ Rodríguez Marín, Francisco, Cervantes y la Inquisición, en "La Esfera" (22 de abril de 1916) 59 .

${ }^{66}$ Rodríguez Marín, Francisco, Cervantes y la Inquisición, en "La Esfera" (22 de abril de 1916) 62.

${ }^{67}$ Batalllon, Marcel Erasmo y España, Fondo de Cultura Económica, México- Buenos Aires $1966^{2}, 794$.

${ }^{68}$ CASTRO, AmÉRICO, Cervantes y la Inquisición, Taurus, Madrid 1960², 191.

${ }^{69}$ ZAPATA, ANTONIO DE, Novus Index librorum Prohibitorum et expurgatorum, Madrid 1632.

${ }^{70}$ San Pablo, 1Cor, 13, 1-3.

${ }^{71}$ Arroyo, Ciriaco, Para entender el Quijote, Ediciones Rialp, Madrid 2005, 10, 317.

${ }^{72}$ LÓPEZ NAVÍo, José, Sobre la frase de la Duquesa "Las obras hechas tibia y flojamente" (don Quijote II, 36), en Anales Cervantinos 9 (1961-1962) 97-112; MORón ARRoYo, CirIACO,
} 


\section{La gracia gratis data}

Sancho tiene virtud para desencantar a Dulcinea. La tuvo para resucitar a Altisidora. Se queja de que sus disciplinas y "gotas de sangre", que le devuelvan la vida, no le valgan nada, cuando otros cobran por matar. "No quiero creer que me haya dado el cielo la virtud que tengo para que yo la comunique de bóbilis, bóbilis. (Don Quijote) puesto que tu virtud es gratis data, que no te ha costado estudio alguno, más que estudio es recibir martirios en tu persona"73. Los teólogos distinguían gracia gratis data, que da Dios a quien le place, a buenos y a malos, a favor de los demás, como es el don de lenguas, de profecía, de sanar enfermos. "Un religioso de la orden de san Jerónimo, que tenía gracia y ciencia particular en hacer que los mudos entendieran y en cierta manera hablasen, y en curar locos, tomó a su cargo de curar a Vidriera, movido de caridad, y le curó y sanó, y volvió a su primer juicio, entendimiento y discurso"74.

\section{Otros textos: la gracia, luz y amor}

La gracia es adorno del alma. Se dice en la elegía del cardenal don Diego de Espinosa. "Acá nos quedarán por tus trofeos / tu cristiandad, valor y gracia extraña / de alma santa santísimos arreos"75. La gracia es luz, sol divino. Como el sol calienta la tierra, la lluvia convertida alegra el suelo y da a los hombres vida. "Y de esta misma suerte / el sol divino te regala y toca / y en tal humor se convierte / que, con tu pluma, apoca / la sequedad de la ignorancia nuestra / y a ciencia santa y santa vida adiestra" ${ }^{\text {. }}$. No faltan las maravillas de la gracia, celebradas en una poesía con motivo de la beatificación de la madre Teresa de Jesús. "Dios para ser tuya te guardaba. / Creciste, y fue creciendo en ti la gana / de obrar en proporción de los favores / con que te regaló la mano eterna, / tales que, al parecer, se alzó a mayores / contigo alegre Dios en la mañana / de tu florida edad humilde y tierna; / y así tu ser gobierna / que poco a poco subes / sobre las densas nubes / de la

Nuevas meditaciones del "Quijote", Editorial Gredos, Madrid 1976, 3, 129-134; AMEZúA MaYo, Agustín G. DE, Novelas Ejemplares, t. I, Madrid 1982, 5, III, 163-169; MuÑoz IgLesias, SALVAdor, Lo religioso en el Quijote, Toledo 1989, XIV,303-306; AlCALÁ, ÁnGEL, Literatura y ciencia ante la Inquisición española, Ediciones del Laberinto, Madrid 2001, 6, 114-117.

${ }^{73} \mathrm{QM}, \mathrm{II}, \mathrm{LXXI}, 1310$.

${ }^{74} \mathrm{LV}, 209$.

${ }^{75} \mathrm{VP}-\mathrm{PV}, 222$

${ }^{76}$ VP-PV, 245. 
suerte mortal, y así levantas / tu cuerpo al cielo, sin fijar las plantas, / que ligero tras sí el alma le lleva / a las regiones santas / con nueva suspensión, con virtud nueva"77. Como en otros textos se recurre a la gracia para describir el amor. Gracia y amor son una realidad humana. "Allí su humildad te muestra santa; / acullá se desposa Dios contigo: / aquí misterios altos te revela. /Tierno amante se muestra, dulce amigo, / y, siendo tu maestro, te levanta / al cielo, que señala por tu escuela; / Parece se desvela / en hacerte mercedes; / rompe rejas y redes / para buscarte el Mágico divino, / tan tu llegado siempre y tan contino / que, si algún afligido a Dios buscará, / acortando camino / en tu pecho o en su celda le hallará"78. La gracia libera y deleita. "Que lo goces es justo / en éxtasis divino / por todos los caminos / por donde Dios llevar a un alma sabe, / para darle de sí cuanto ella cabe, / y aun la ensancha, dilata y engrandece / y, con amor suave, / a sí y de sí las junta y enriquece" $"$.

Sancho advierte que es pecado dar libertad a los galeotes, pues van encadenados por sus maldades. La palabra pecado despierta en don Quijote la palabra gracia. "A los caballeros andantes no les toca ni atañe averiguar a los afligidos, encadenados y opresos que encuentran por los caminos van de aquella manera o están en aquella angustia por sus culpas o por sus gracias"80. La gracia es el amor de Dios y la amistad divina no se puede perder por nada humano. Lotario desaconsejaba a Anselmo de sus propósitos, porque, como dijo un poeta gentil, los amigos "que no se habían de valer de su amistad en cosas que fuesen contra Dios. Pues si esto sintió un gentil de amistad, ¿cuánto mejor es que lo sienta un cristiano, que sabe que por ninguna humana ha de perder la amistad divina? Y cuando el amigo tirase tanto la barra, que pusiese aparte los respetos del cielo por acudir a los de su amigo, no ha de ser por cosas ligeras y de poco momento, sino por aquellas en que vaya la honra y la vida de su amigo"

En el Persiles se habla de las gracias del jubileo. "Pidió que consigo la llevasen a Roma, que, había sido peregrina en culpas, quería procurar serlo en gracias, si el cielo se las concedía en que con ellos la llevasen" 82 . Yo salí de mi casa a Roma "las arcas del tesoro de la Iglesia y comunicándonos, como en Año Santo, las infinitas gracias que en él suelen ganarse" ${ }^{83}$. De la

${ }^{77}$ VP- PV, 280-281.

${ }^{78}$ VP-PV. 281.

${ }^{79}$ VP-PV, 282.

${ }^{80} \mathrm{QM}, \mathrm{I}, \mathrm{XXX}, 378$.

${ }^{81} \mathrm{QM}, \mathrm{I}, \mathrm{XXXIII}, 417$.

82 PS, III, IV, 461.

${ }^{83}$ PS, III, IX, 520. 
Virgen se dice que es un alcázar soberano con huertos, cipreses, palmas, fuentes perennes, "clarísimos espejos / que dan lumbre de gracias cerca y lejos" 84 .

\section{Resumen}

La gracia nos hace más de Dios, nos introduce en el evangelio. Es la gracia que, con su unción, nos hace experimentar Cristo, nuestro legislador y maestro y es suave. Es la gracia que predica don Quijote a los que no saben perdonar a sus enemigos y quieren vengarse de ellos. Libros, acontecimientos, encuentros, diálogos, obras buenas van dejando sus semillas. La gracia es luz de todo hombre que viene a este mundo. Es la infinita misericordia de Dios, que no amenguarán los pecados de los hombres. Quizás hoy estemos en mejores condiciones que nunca para valorar este cristianismo. Dios no es algo lejano, sino presente y misericordioso. Es la Providencia amorosa, que cada uno acepte su responsabilidad. El hombre no solo cuenta con su razón para orientarse. Después de todo lo que llevamos dicho, creo que estas son las creencias religiosas fundamentales.

\footnotetext{
${ }^{84} \mathrm{PS}, \mathrm{III}, \mathrm{V}, 478$.
} 